\title{
Does Helicobacter pylori infection increase gastric sensitivity in functional dyspepsia?
}

F Mearin, X de Ribot, A Balboa, A Salas, M J Varas, M Cucala, R Bartolomé, J R Armengol, J-R Malagelada

\begin{abstract}
The role of Helicobacter pylori infection in the pathogenesis of functional dyspepsia is debated. It is known that a substantial fraction of dyspeptic patients manifest a low discomfort threshold to gastric distension. This study investigated the symptomatic pattern in $27 \mathrm{H}$ pylori positive and 23 $H$ pylori negative patients with chronic functional dyspepsia, and potential relations between infection and gastric hyperalgesia. Specific symptoms (pain, nausea, vomiting, bloating/fullness, early satiety) were scored from 0 to 3 for severity and frequency (global symptom scores: 0-15). The mechanical and perceptive responses to gastric accommodation were evaluated with an electronic barostat that produced graded isobaric distensions from 0 to 20 $\mathrm{mm} \mathrm{Hg}$ in $2 \mathrm{~mm} \mathrm{Hg}$ steps up to $600 \mathrm{ml}$. Gastric compliance (volume/pressure relation) and perception (rating scale: 0-10) were quantified. Standard gastrointestinal manometry and recorded phasic pressure activity at eight separate sites during fasting and postprandially were also assessed. $H$ pylori positive and $H$ pylori negative patients manifested similar severity and frequency of specific symptoms and global symptom scores (mean (SEM)) (severity: 9.5 (2.0) v 9.0 $(2 \cdot 1)$; frequency: $10.8(2 \cdot 0) v 9.7(2 \cdot 2))$. No differences were seen either in gastric compliance (53 (4) $\mathrm{ml} / \mathrm{mm}$ Hg $v 43$ (3) $\mathrm{ml} / \mathbf{m m ~} \mathrm{Hg}$ ) or in gastric perception of distension (slope: $0.50 \quad(0.05)$ v 0.53 $(0 \cdot 06))$. Postprandial antral motility was significantly decreased in $H$ pylori positive patients (two hours motility index: $10.4(0.6) v 12.6(0.5) ; p<0.05)$. It is concluded that $H$ pylori infected patients with functional dyspepsia present no distinctive symptoms by comparison with $H$ pylori negative counterparts and $H$ pylori infection is associated with diminished postprandial antral motility but it does not increase perception of gastric distension.

(Gut 1995; 37: 47-51)
\end{abstract}

Keywords: functional dyspepsia, Helicobacter pylori, gastric perception, gastric barostat, gastric compliance, gastrointestinal manometry.

Functional dyspepsia is a highly prevalent clinical syndrome whose aetiology and pathophysiology are poorly understood. Infectious,

secretory, motor, psychological, and perceptive factors have been implicated as possible aetiopathogenic mechanisms. ${ }^{12}$ Among these, gastric infection by Helicobacter pylori has been incriminated as a cause of functional dyspepsia although published results are controversial. In some therapeutic trials dyspeptic symptoms improved after $H$ pylori eradication ${ }^{34}$ but in other trials no clinical improvement was detected. ${ }^{56}$ Other investigators have proposed an association between $H$ pylori positive functional dyspepsia and a specific subgroup of symptoms, mainly abdominal pain. ${ }^{7}$

Pathophysiological abnormalities in functional dyspepsia include motor and sensory disturbances. Antral hypomotility occurs in 25 to $40 \%$ of patients and a similar proportion shows delayed gastric emptying. ${ }^{8}$ Possible relations between $H$ pylori infection and these motor disturbances in dyspeptic patients have been investigated with conflicting results. For instance some authors have found gastric emptying to be delayed in infected patients ${ }^{9}$ while others have not. ${ }^{7} 10$

Sensory disturbances in functional dyspepsia are manifested by a diminished perception threshold to gastric distension in the presence of normal intestinal and somatic perception. ${ }^{11} 12$ So far, however, the hypothesis that mucosal inflammation resulting from $H$ pylori infection causes gastric hypersensitivity in dyspeptic patients had not been formally explored.

The aim of this study was to investigate whether patients with chronic functional dyspepsia infected by $H$ pylori present different clinical, motor, and visceral perception features than non-infected patients.

\section{Methods}

\section{Patients and healthy volunteers}

Fifty consecutive patients with the diagnosis of chronic functional dyspepsia participated in the study: 27 were $H$ pylori positive (seven men and 20 woman; mean age: 33 years; age range: $18-55)$ and 23 were $H$ pylori negative (four men and 19 women; mean age: 35 ; age range: 19-61). Patients were submitted to our hospital, as a referral centre, from general practice and other hospitals for complete evaluation. Twelve healthy volunteers (seven men and five women; mean age: 24; age range: 22-26) served as controls. All participants stopped taking any drugs for at least 72 hours before the study. The protocol for the study had been previously approved by the institutional review board of the Hospital General Vall d'Hebron and informed consent
Correspondence to: Dr F Mearin, Digestive System Research Unit, d'Hebron, 08035 Barcelona, Spain.

Accepted for publication 10 November 1994 
was obtained from all participants in the study.

Inclusion criteria for dyspeptic patients were (a) presence of at least two symptoms of a five symptom complex (upper abdominal pain, bloating/fullness, early satiety, nausea, and vomiting); (b) moderate to severe intensity of illness defined by a numerical symptom score that is, a sum score higher than 6 (see clinical evaluation); (c) chronic complaints defined by the presence of the dyspeptic symptoms for at least two years before study; (d) absence of biochemical and morphological evidence of gastrointestinal, biliary, and systemic diseases, as established by negative results of physical examination, laboratory tests, upper gut endoscopy and ultrasonography, or oral cholecystogram; (e) absence of history suggestive of previous peptic ulcer disease; (f) absence of symptoms predominantly suggesting gastrooesophageal reflux disease or irritable bowel syndrome; and (g) no previous abdominal surgery other than appendicectomy or hernia repair.

\section{Clinical evaluation \\ Dyspeptic symptoms were evaluated using a questionnaire listing five symptoms: upper abdominal pain, nausea, vomiting, bloating/ fullness, and early satiety. Severity and fre- quency of each symptom were separately eval- uated by a defined numerical score. Severity: 0 , absent; 1 , mild (awareness of symptom but easily tolerated); 2 , moderate (interference with normal activities); 3, severe (incapacitat- ing); total severity score: $0-15$. Frequency: 0 , absent (less than once per month); 1, rarely (less than once per week); 2, occasionally (less than three times per week); 3 , often (more than or three times per week); total frequency score: 0-15. A global symptom index, for each symp- tom and for the total score, was also obtained by multiplying severity by frequency.}

\section{Detection of $\mathrm{H}$ pylori}

In every patient four antral and four fundic biopsy specimens were obtained by endoscopy. $H$ pylori was identified by bacterial culture, direct staining techniques, and in vitro urease production as previously described. ${ }^{13}$ Specimens were processed within two hours after being obtained. Each specimen was smeared into a glass slide, heat fixed, Gram stained, and examined with a $\times 100$ oil immersion lens for a minimum of five minutes. It was

TABLE I Symptom score in chronic functional dyspepsia. Comparison between $\mathrm{H}$ pylori positive and $\mathrm{H}$ pylori negative patients

\begin{tabular}{|c|c|c|c|c|c|c|}
\hline & \multicolumn{2}{|l|}{ Severity } & \multicolumn{2}{|l|}{ Frequency } & \multicolumn{2}{|c|}{ Global symptom index } \\
\hline & $H P(+)$ & $H P(-)$ & $H P(+)$ & $H P(-)$ & $H P(+)$ & $H P(-)$ \\
\hline $\begin{array}{l}\text { Abdominal pain } \\
\text { Nausea } \\
\text { Vomiting } \\
\text { Bloating/fullness } \\
\text { Early satiety } \\
\text { Total symptom score }\end{array}$ & $\begin{array}{l}2.2(0.2) \\
1.8(0.2) \\
1.3(0.2) \\
2.3(0.2) \\
2.0(0.2) \\
9.5(0.4)\end{array}$ & $\begin{array}{l}2 \cdot 2(0 \cdot 2) \\
1 \cdot 8(0 \cdot 3) \\
1 \cdot 1(0 \cdot 3) \\
2 \cdot 3(0 \cdot 2) \\
1 \cdot 7(0 \cdot 2) \\
9 \cdot 0(0.4)\end{array}$ & $\begin{array}{r}2.6(0 \cdot 2) \\
1.9(0 \cdot 2) \\
1.3(0 \cdot 2) \\
2 \cdot 8(0 \cdot 1) \\
2.3(0 \cdot 2) \\
10.8(0 \cdot 4)\end{array}$ & $\begin{array}{l}2.4(0.2) \\
1.7(0.3) \\
1.2(0.3) \\
2.5(0.2) \\
1.9(0.3) \\
9.7(0.5)\end{array}$ & $\begin{array}{r}6.0(0.5) \\
4.3(0 \cdot 6) \\
2.9(0.6) \\
6.7(0.5) \\
5 \cdot 1(0.5) \\
25.0(1 \cdot 2)\end{array}$ & $\begin{array}{r}5 \cdot 8(0 \cdot 6) \\
4 \cdot 0(0 \cdot 7) \\
2 \cdot 7(0 \cdot 7) \\
6 \cdot 2(0 \cdot 6) \\
4 \cdot 5(0 \cdot 8) \\
23 \cdot 2(1 \cdot 4)\end{array}$ \\
\hline
\end{tabular}

Data presented as mean (SEM). HP (+): $H$ pylori positive; HP (-): $H$ pylori negative;

Global symptom index: severity $\times$ frequency. also cultured on a $H$ pylori selective medium: brain-heart infusion agar with $7 \%$ horse blood, $1 \%$ isovitalex, vancomycin $(6 \mathrm{mg} / \mathrm{l})$, nalidixic acid $(20 \mathrm{mg} / \mathrm{l})$, and amphotericin $B(2 \mathrm{mg} / \mathrm{l})$. The plates were incubated at $37^{\circ} \mathrm{C}$ in a microaerophilic atmosphere for seven days. $H$ pylori strains were identified by the following tests: Gram stain, oxidase, catalase, urease, growth at $42^{\circ} \mathrm{C}$ in microaerophilic atmosphere and cephalothin, and nalidixic acid sensitivity.

A patient was considered infected by $H$ pylori if the bacterial culture was positive or, when negative, in the presence of all three following results: positive Gram stain, positive urease test, and visualisation of compatible micro-organisms in the biopsy specimen.

\section{Gastrointestinal manometry}

The procedure has been previously described in detail. ${ }^{14}$ In brief, an eight lumen orointestinal tube ( $5 \mathrm{~mm}$ OD) was placed under fluoroscopic guidance so that six recording sites (1 $\mathrm{cm}$ apart) lay across the gastroduodenal junction and two aboral recording sites $(10 \mathrm{~cm}$ apart) in the descending and distal duodenum, respectively. The probe was connected to a low compliance manometric perfusion system. ${ }^{15}$ Antrointestinal pressure activity was continuously recorded on an eight channel paper polygraph (Dynograph Recorder R611, SensorMedics, Anaheim, CA) for three hours fasting and for two hours after ingestion of a $435 \mathrm{kcal}$ solid liquid meal.

\section{Measurement of perception to gastric distension}

We used this test specifically to evaluate the perception elicited by intragastric distension as well as the gastric compliance (volume/ pressure relation). The procedure was performed by means of an electronic barostat ${ }^{16}$ to produce standardised gastric distension, as described.

After an overnight fast, the bag of the barostat, finely folded, was introduced through the mouth into the stomach. To unfold the intragastric bag, one lumen of the connecting tube was connected to a pressure transducer, and the bag was slowly inflated through the other lumen of the tube with $300 \mathrm{ml}$ of air. The bag was then completely deflated and connected to the barostat. Pressure and volume inside the intragastric bag were continuously recorded on a paper polygraph (model 1600, MFE, Salem, NH).

Participants were placed in a $30^{\circ}$ recumbent position and were asked to relax comfortably. Using the pressure selection dial of the barostat, intrabag pressure was gradually increased by $2 \mathrm{~mm} \mathrm{Hg}$ stepwise increments every three minutes. Graded distension was induced from $0 \mathrm{~mm} \mathrm{Hg}$ (atmospheric pressure) up to the pressure value that first provided an intrabag volume $>600 \mathrm{ml}$ or when the participants reported discomfort $($ score $=8)$. Perception of gastric distension was scored at each pressure step using a rating scale graded from 0 to 10 . We specifically measured perception of upper abdominal 
TABLE II Gastroduodenal manometric data during the fasting period

\begin{tabular}{lccc}
\hline & \multicolumn{2}{l}{ Functional dyspepsia } & Healthy \\
\cline { 2 - 3 } & $H P(+)$ & $H P(-)$ & controls \\
\hline Duration of duodenal IMMC (min) & $105(8)$ & $104(1)$ & $107(10)$ \\
Total & $58(8)$ & $60(7)$ & $61(10)$ \\
Phase I & $39(7)$ & $36(5)$ & $43(9)$ \\
Phase II & $6(1)$ & $6(1)$ & $8(1)$ \\
Phase III & $1 \cdot 0(0 \cdot 1)$ & $1 \cdot 4(0 \cdot 2)$ & $1 \cdot 2(0 \cdot 2)$ \\
Number of gastric phases III & $2 \cdot 2(0 \cdot 1)$ & $2 \cdot 1(0 \cdot 2)$ & $2 \cdot 3(0 \cdot 1)$ \\
Number of duodenal phases III & $14(2)$ & $10(1)$ & $12(2)$ \\
Propagation velocity of duodenal phase III (cm/min) & & & \\
\hline
\end{tabular}

Data presented as mean (SEM). IMMC: interdigestive migrating motor complex.

sensation. Before the study, participants were informed of the types of potential sensations (upper abdominal pressure, fullness, bloating, and nausea) to be scored. These symptoms were selected as being the more frequent sensorial responses to gut distension, previously established by specific questionnaires in our laboratory. ${ }^{56}$ The assessment of perception was performed by means of a manually activated scale as the intensity of upper abdominal sensation. Intensity scores were defined as follows: 0 , absent sensation; 1 and 2 , faint sensation; 3 and 4 , mild sensation; 5 and 6 , moderate sensation; 7 and 8 , uncomfortable sensation; and 9 and 10, painful sensation. However, as specified, distensions were discontinued if the discomfort level (score 8) was reached.

\section{Data analysis}

To measure gastric compliance we averaged intrabag volumes during each pressure step and volumes at each pressure level were corrected for air compressibility using Boyle's law $\left(\mathrm{P}_{1} \mathrm{~V}_{1}=\mathrm{P}_{2} \mathrm{~V}_{2}\right)$. A compliance curve (volume $v$ pressure) was then constructed. In each subject, we defined the minimal distending pressure as the first pressure level that provided an intragastric volume of $\geqslant 30 \mathrm{ml}$; this pressure

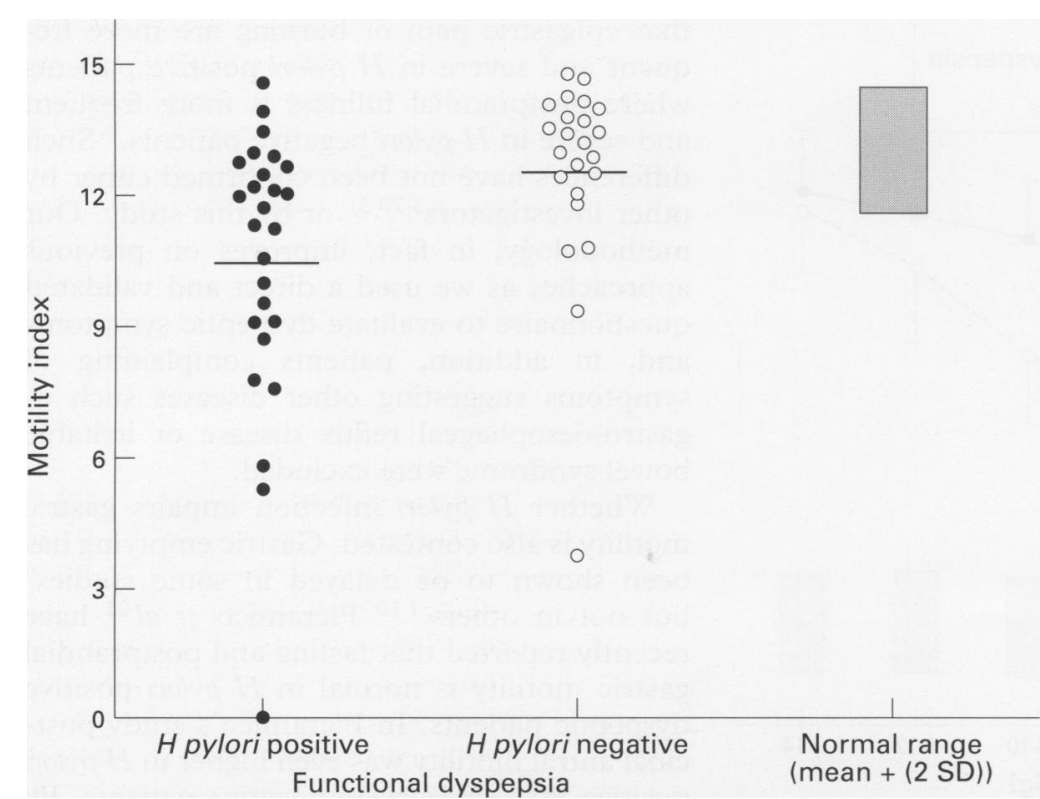

Figure 1: Two hour postprandial motility index. Note that $13 \mathrm{H}$ pylori positive patients had hypomotility whereas only four of the $\mathrm{H}$ pylori negative did. (Values lower than mean $(-2 S D)$ of healthy volunteer values.) ( $p<0.05 \mathrm{H}$ pylori positive patients versus $\mathrm{H}$ pylor negative patients). level accounted for intra-abdominal pressure. Perception of gastric distension measured by the score system described above was plotted at each pressure level starting from the minimal distending pressure.

Antrointestinal manometric tracings were visually analysed as previously described. ${ }^{14}$ During fasting (three hours), we determined the duration of the interdigestive migrating motor complex at the duodenal level and of each of its different phases, the number of episodes of phase III activity in the antrum and in the intestine, and the propagation velocity of duodenal phase III. In the two hour postcibal period, phasic pressure activity in the most distal antral recording site was analysed using a motility index: $M I=\log _{e}$ [(no of waves $\times$ sum of amplitude)+1]. Duodenal motility was analysed qualitatively according to the criteria of Stanghellini et al. ${ }^{17}$

Results are expressed as the mean (SEM) values for each parameter measured. Statistical comparisons were performed using Student's $t$ test with unpaired analysis for intergroup comparisons. A p value of $<0.05$ was chosen as the significance value.

\section{Results}

\section{Clinical data}

The duration of the disease estimated from onset of clinical symptoms to the time of study was similar in $H$ pylori positive and $H$ pylori negative patients $(5.63(0.86)$ years $v 7 \cdot 13$ $(1 \cdot 15)$ years, respectively). Both groups of patients were similar with regard to race, social status, and smoking habit (13 and 15 nonsmokers in each group respectively); no alcohol abuse was present in any patient. Also, no differences between $H$ pylori positive and negative patients were detected in severity or frequency of individual dyspeptic symptoms, in total symptom score or in symptom indexes (Table I).

\section{Gastrointestinal manometric data}

No significant differences were found between $H$ pylori positive and $H$ pylori negative patients with respect to fasting manometric data; results were similar to those obtained in healthy controls (Table II). The two hour postprandial antral motility index was significantly lower, however, in $H$ pylori positive patients than in $H$ pylori negative patients $(10.4(0.6) v 12.6(0.5) ; \mathrm{p}<0.05)$. Moreover 12 of $26 \mathrm{H}$ pylori positive patients had postcibal antral hypomotility (values lower than the mean (2 SD) of healthy volunteer values) compared with only four of the $24 \mathrm{H}$ pylor negative patients (Fig 1). In one $H$ pylori positive patient the antral motility index could not be calculated because of technical difficulties.

Only four patients showed evidence of abnormal duodenal motility during the postprandial period: two patients (both $H$ pylori positive) showed evident duodenal hypomotility and another two (both $H$ pylori 
TABLE III Symptom score in chronic functional dyspepsia. Comparison between subgroups of $\mathrm{H}$ pylori positive patients with normal motility $(n=13)$ and with hypomotility $(n=13)$

\begin{tabular}{|c|c|c|c|c|c|c|}
\hline & \multicolumn{2}{|l|}{ Severity } & \multicolumn{2}{|l|}{ Frequency } & \multicolumn{2}{|c|}{ Global symptom index } \\
\hline & $\begin{array}{l}\text { Normal } \\
\text { motility }\end{array}$ & Hypomotility & $\begin{array}{l}\text { Normal } \\
\text { motility }\end{array}$ & Hypomotility & $\begin{array}{l}\text { Normal } \\
\text { motility }\end{array}$ & Hypomotility \\
\hline $\begin{array}{l}\text { Abdominal pain } \\
\text { Nausea } \\
\text { Vomiting } \\
\text { Bloating/fullness } \\
\text { Early satiety } \\
\text { Total symptom score }\end{array}$ & $\begin{array}{r}2.3(0.2) \\
1.6(0.3) \\
1.6(0 \cdot 3) \\
2.5(0 \cdot 2) \\
2.0(0.3) \\
10.0(0 \cdot 6)\end{array}$ & $\begin{array}{l}1.9(0.2) \\
2.0(0.3) \\
1.2(0.4) \\
2.0(0.3) \\
1.8(0.2) \\
8.9(0.5)\end{array}$ & $\begin{array}{r}2.7(0.1) \\
1.8(0.3) \\
1.5(0.3) \\
2.8(0.1) \\
2.4(0.3) \\
11.2(0.7)\end{array}$ & $\begin{array}{r}2 \cdot 5(0 \cdot 3) \\
2 \cdot 1(0 \cdot 3) \\
1 \cdot 1(0 \cdot 3) \\
2 \cdot 7(0 \cdot 2) \\
2 \cdot 2(0 \cdot 2) \\
10 \cdot 5(0 \cdot 4)\end{array}$ & $\begin{array}{r}6 \cdot 3(0 \cdot 7) \\
3 \cdot 8(0 \cdot 9) \\
3 \cdot 5(0 \cdot 9) \\
7 \cdot 1(0 \cdot 6) \\
5 \cdot 5(0 \cdot 9) \\
26 \cdot 3(2 \cdot 1)\end{array}$ & $\begin{array}{r}5 \cdot 4(0 \cdot 8) \\
4 \cdot 8(0.9) \\
2 \cdot 6(1 \cdot 0) \\
5 \cdot 9(0.9) \\
4 \cdot 2(0 \cdot 6) \\
23 \cdot 0(1 \cdot 3)\end{array}$ \\
\hline
\end{tabular}

Data presented as mean (SEM). Global symptom index: severity $\times$ frequency.

negative) showed bursts of non-propagated phasic pressure activity.

When comparing the clinical data in the subgroup of $H$ pylori positive patients who display postprandial antral hypomotility $(n=13)$ with the subgroup with normal motility $(n=13)$ no significant differences were found (Table III). Surprisingly, symptoms suggestive of delayed gastric emptying such as early satiety or postprandial fullness were slightly higher in the subgroup of patients without hypomotility; the same occurred for vomiting and abdominal pain whereas nausea was slightly more prominent in $H$ pylori positive patients with postprandial hypomotility.

\section{Perception of gastric distension and gastric compliance}

During intubation and basal periods patients reported no symptoms. Stepwise distension of the stomach induced similar abdominal symptoms in dyspeptic $H$ pylori positive and $H$ pylori negative patients. Both groups experienced significantly more abdominal discomfort than healthy subjects at the same distending levels (Fig 2).

Gastric compliance (volume/pressure relation) was also similar in $H$ pylori positive and negative patients, and did not differ from

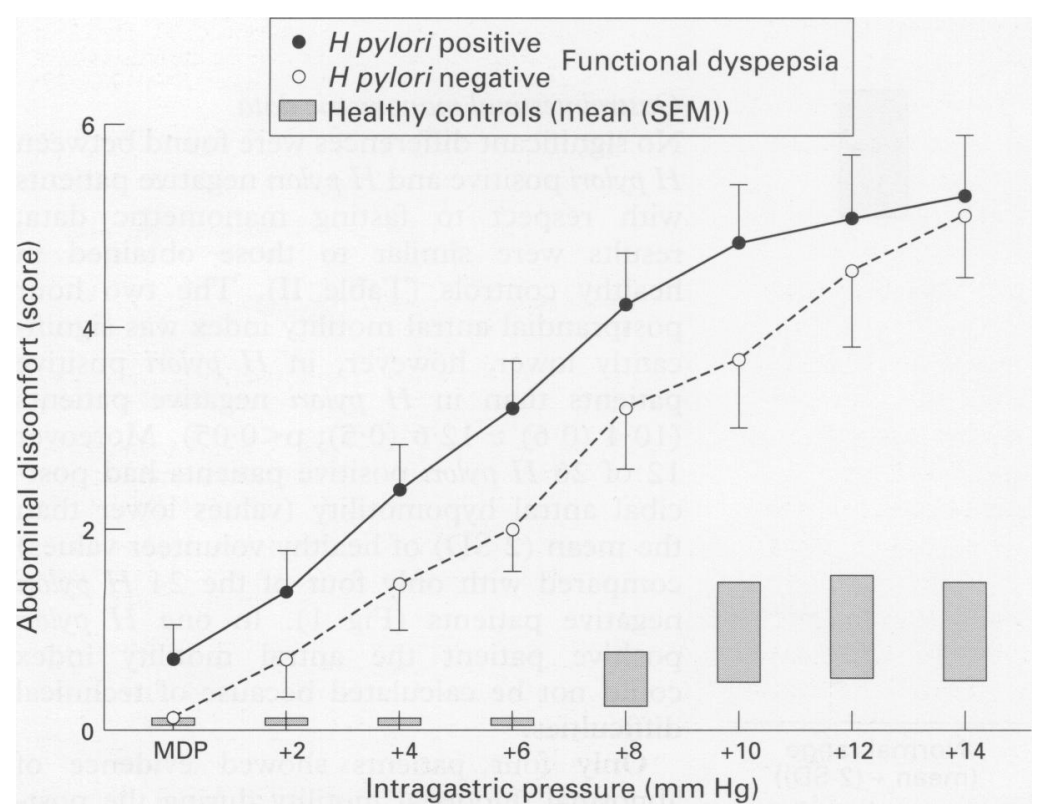

Figure 2: Abdominal discomfort elicited by gastric distension is similar in patients with functional dyspepsia with or without $\mathbf{H}$ pylori infection. Both groups experienced significantly more abdominal discomfort than healthy subjects. $M D P=$ minimal distending pressure. values obtained in healthy controls (Fig 3).

\section{Discussion}

Functional dyspepsia is currently assumed to represent a symptom complex, which includes different pathophysiological mechanisms but produces a stereotyped clinical picture. Diverse abnormalities in motor and sensory upper gut function have been identified. We have shown that, as a group, dyspeptic patients have increased gastric perception to distension, suggesting a change in the afferent sensory pathway. ${ }^{11}$ As inflammation may enhance both somatic and visceral sensitivity, referred to as hyperalgesia, 1819 we investigated whether gastric inflammation caused by $H$ pylori infection increases gastric perception to distension. Our results disprove this hypothesis as we found that the perceptive response was similar in $H$ pylori positive and $H$ pylori negative patients. Confirming our previous results, however, ${ }^{11}$ we found that in both groups intragastric perception was increased when compared with a healthy control group. Thus, gastric inflammatory changes induced by $H$ pylori infection do not seem to be responsible for the gastric hyperalgesia seen in functional dyspepsia.

We also investigated whether dyspeptic patients infected by $H$ pylori manifested a specific symptom pattern. It has been reported that epigastric pain or burning are more frequent and severe in $H$ pylori positive patients where postprandial fullness is more frequent and severe in $H$ pylori negative patients. ${ }^{7}$ Such differences have not been confirmed either by other investigators 52021 or by this study. Our methodology, in fact, improves on previous approaches as we used a direct and validated questionnaire to evaluate dyspeptic symptoms and, in addition, patients complaining of symptoms suggesting other diseases such as gastro-oesophageal reflux disease or irritable bowel syndrome were excluded.

Whether $H$ pylori infection impairs gastric motility is also contested. Gastric emptying has been shown to be delayed in some studies 9 but not in others. ${ }^{710}$ Pieramico et al ${ }^{21}$ have recently reported that fasting and postprandial gastric motility is normal in $H$ pylori positive dyspeptic patients. In Pieramico's study postcibal antral motility was even higher in $H$ pylori positive than in $H$ pylori negative patients. By contrast, we have found postprandial antral motor activity to be significantly decreased in dyspeptic patients infected by $H$ pylori. This 


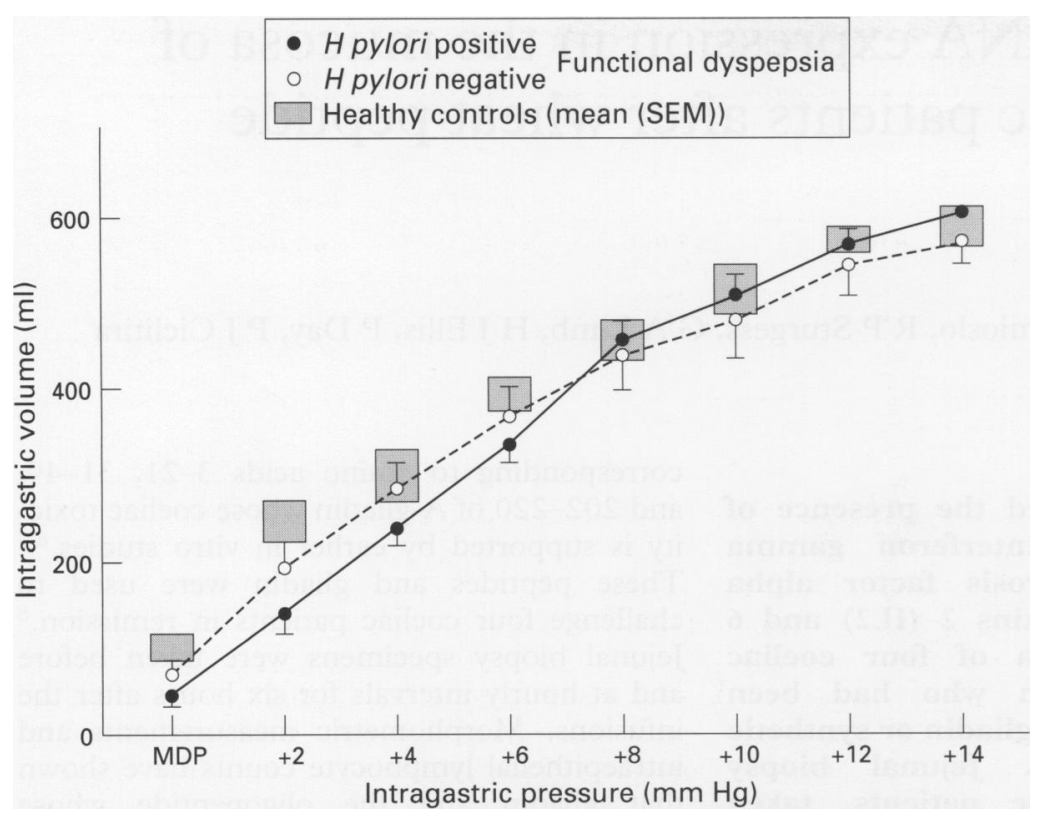

Figure 3: Gastric compliance (volume-pressure relation) is similar in patients with functional dyspepsia with or without $\mathbf{H}$ pylori infection. Values did not differ from those obtained in healthy subjects.
(1) eradication is not mandatory for symptom relief in chronic functional dyspepsia, and (2) drugs affecting visceral sensitivity can be effective regardless of $H$ pylori status.

1 Barbara L, Camilleri M, Corinaldesi R, Crean GP, Heading RC, Johnson AG, et al. Definition and investigation of RC, Johnson AG, et al. Definition and

2 Talley NJ, Colin-Jones D, Koch KL, Koch M, Nyrén O, Stanghellini V. Functional dyspepsia: a classification with guidelines for diagnosis and management. Gastroenterology International 1991; 4: 145-60.

3 Rokkas T, Pursey C, Uzorchina E, Dorrington L, Simmons NA, Filipe MI, et al. Non-ulcer dyspepsia and short term De-Nol therapy: a placebo controlled trial with particular reference to the role of Campylobacter pylori. Gut 1988; 29: 1386-91.

4 Goh KL, Parasakthi N, Pen SC, Wong NW, Lo YL, Puthuchearsy SD. Helicobacter pylori infection and nonulcer dyspepsia: the effect of treatment with colloidal bismuth subcitrate. Scand $\mathcal{f}$ Gastroenterol 1991; 26: bismuth $1123-31$.

5 Loffeld RJLF, Potters HVPJ, Stobberingh F, Flendrig JA, Van Spreeuwel JD, Arends JW. Campylobacter associated gastritis in patients with non-ulcer dyspepsia: a double blind placebo controlled trial with colloid bismuth subcitrate. Gut 1989; 30: 1206-12.

6 Patchett S, Beattie S, Leen E, Keane C, O'Morian C. Eradicating Helicobacter pylori and symptoms of nonulcer dyspepsia. BMF 1991; 303: 1238-40.

7 Tucci A, Corinaldesi R, Stanghellini V, et al. Helicobacter pylori infection and gastric function in patients with chronic idiopathic dyspepsia. Gastroenterology 1992; 103: 768-74.

8 Mearin F, Malagelada J-R. Upper gut motility and perception in functional dyspepsia. Eur $\mathcal{F}$ Gastroenterol Hepatol 1992; 4: 615-21.

9 Wegener M, Börsch G, Schaffstein J, et al. Are dyspeptic symptoms in patients with Campylobacter pylori-associated type B gastritis linked to delayed gastric emptying? ated type B gastritis linked to delayed

discrepancy cannot be explained by technical differences as the manometric procedure, the recording period, the type of meal, and the data analysis were almost identical. The difference could be in the selection of the patients with more chronic complaints in our dyspeptic subjects (two years minimum) than in those of Pieramico et al (three months minimum). It is conceivable that the motor response to $H$ pylori infection could be time dependent as it is for gastric secretion. Nevertheless, the significance of $H$ pylori infection in the pathogenesis of gastric hypomotility in functional dyspepsia remains in doubt as none of the upper gut motor abnormalities previously reported seem to correlate strongly with any particular type or intensity of dyspeptic symptoms. ${ }^{22} 23$ In fact, we found no significant differences when comparing the clinical data of $H$ pylori positive patients with or without gastric hypomotility. Moreover, prokinetic drugs tend to consistently show pharmacological effectivity in connecting hypomotility and impaired emptying but, such positive motor effects are not invariably associated with symptom improvement. 2425 It should also be pointed out that an inverse correlation between gastric mucosal inflammation and postprandial antral motility has been described in peptic ulcer disease, ${ }^{26}$ but such a correlation is not apparent in patients with chronic functional dyspepsia. ${ }^{21}$

In summary, the symptom complex associated with $H$ pylori positive functional dyspepsia is not different from that in $H$ pylori negative functional dyspepsia. Moreover, $H$ pylori infection cannot be held responsible for the gastric hyperalgesia exhibited by many dyspeptic patients. Although postcibal antral motility is somewhat diminished in $H$ pylori positive patients, such a finding may well represent an epiphenomenon as no relation with symptoms could be shown. These findings could have important therapeutic consequences, that is:
10 Barnett $\mathrm{L}$, Behler EM, Appelman HD, Elka GH. Campylobacter pylori is not associated with gastroparesis. Dig Dis Sci 1989; 34: 1677-80.

11 Mearin F, Cucala M, Azpiroz F, Malagelada J-R. The origin of symptoms on the brain-gut axis in functional dyspepsia. Gastroenterology 1991; 101: 999-1006. hypersensitivity and reflex hyporeactivity in functional dyspepsia. Gastroenterology 1991; 100: A431.

13 Hazell SL. Cultural techniques for the growth and isolation of Helicobacter pylori. In: Goodwin CS, Worsley BW. Helicobacter pylori biology and clinical practice. Boca Raton,

14 Malagelada J-R, Stanghellini V. Manometric evaluation of functional upper gut symptoms. Gastroenterology 1985; 88: 1223-31.

15 Arndorfer RC, Stef JJ, Dodds WJ, Lineham JH, Hogen WJ. Improved infusion system for intraluminal esophageal manometry. Gastroenterology 1977; 73: 23-7.

16 Azpiroz F, Malagelada J-R. Gastric tone measured by an

17 Stanghellini V, Camilleri M, Malagelada J-R. Chronic idiopathic intestinal pseudo-obstruction: clinical and intestinal manometric findings. Gut 1987; 28: 5-12.

18 Kocher L, Anton F, Reeh PW, Handwerker HO. The effect of carrageenan-induced inflammation on the sensitivity of unmyelinated skin nociceptors in the rat. Pain 1987; 29: unmyelinat

19 Häbler H-J, Jänig W, Koltzenburg M. Activation of uäbler H-J, Jänig W, Koltzenburg $M$. Activation of
unmyelinated afferent fibers by mechanical stimuli and

20 Börsch G, Schmidt G, Wegener M, Sandmann M, Adamek $\mathrm{R}$, Leverkus $\mathrm{F}$, et al. Campylobacter pylori: prospective analysis of clinical and histological factors associated with colonization of the upper gastrointestinal tract. Eur $\mathfrak{f}$ Clin Invest 1988; 18: 133-8.

21 Pieramico O, Distchuneit $\mathrm{H}$, Malfertheiner $P$. Gastrointestinal motility in patients with non-ulcer dyspepsia: a role for Helicobacter pylori infection? $\mathrm{Am} \mathfrak{f}$ pepsia: a role for Herol 1993; 88: 364-8.

22 Talley NJ, Shuter B, McCrudden G, Jones M, Hoschir R, Piper DW. Lack of association between gastric emptying Piper DW. Lack of association between gastric emptying
of solids and symptoms in nonulcer dyspepsia. $\mathcal{f}$ Clin of solids and symptoms in no.

23 Waldron B, Cullen PT, Kumar R, Smith D, Jankowski J, Hopwood D, et al. Evidence for hypomotility in nonulcer dyspepsia: a prospective multifactorial study. Gut 1991, 32: $246-51$.

24 Testoni PA, Bagnolo F, Fanti L, Passaretti S, Tittobello A Longterm oral cisapride improves interdigestive antroduo-

25 Corinaldesi R, Stanghellini V, Raiti C, Rea E, Salgemini R, Barbara L. Effect of chronic administration of cisapride on gastric emptying of a solid meal and on dyspeptic symptoms in patients with idiopathic gastroparesis. Gut 1990; 28: 300-5.

26 Moore SC, Malagelada J-R, Shorter RG, et al. Interrelationships among gastric mucosal morphology, 1986; 31: 673-84.
12 Coffin B, Azpiroz F, Malagelada J-R. Selective gastric electronic barostat in health and postsurgical gastroparesis. Gastroenterology 1987; 92: 934-43. inflammation of the urinary bladder in the car. $\mathcal{F}$ Physio 1990; 425: 545-62. denal motility in dyspeptic patients. Gut 1990; 31: 286-90 